\title{
Urodynamic Assessment of Neuronal Intranuclear Inclusion Disease
}

\author{
Yosuke Aiba $^{a}$ Ryuji Sakakibara ${ }^{a}$ Fang-Ching Lee $^{b}$ Fuyuki Tateno $^{a}$ \\ aNeurology, Internal Medicine, Sakura Medical Center, Toho University, Sakura, Japan; bUrology, Sakura Medical \\ Center, Toho University, Sakura, Japan
}

\section{Keywords}

Neuronal intranuclear inclusion disease - Dementia .

Bladder dysfunction - Urodynamics - Leukoencephalopathy ·

Autonomic neuropathy

\begin{abstract}
Neuronal intranuclear inclusion disease (NIID) is a disease that causes leukoencephalopathy (dementia) and peripheral neuropathy (variable manifestation including bladder dysfunction). This is the first urodynamic report to show that bladder dysfunction in NIID is a combination of detrusor overactivity, decreased bladder sensation, large post-void residual, and neurogenic changes in the sphincter electromyogram. This report will help managing bladder dysfunction in NIID.

(C) 2020 The Author(s)

Published by S. Karger AG, Basel
\end{abstract}

\section{Introduction}

Neuronal intranuclear inclusion disease (NIID) is a rare progressive neurodegenerative disorder characterized by eosinophilic hyaline inclusions which are widely observed in neuronal and somatic cells $[1,2]$. The inclusions proved to have positive immunostaining for ubiquitin, small ubiquitin-related modifier, polyglutamine,

karger@karger.com www.karger.com/ene

Karger"
(C) 2020 The Author(s)

Published by S. Karger AG, Basel

Karger

Open access

This article is licensed under the Creative Commons AttributionNonCommercial-NoDerivatives 4.0 International License (CC BYNC-ND) (http://www.karger.com/Services/OpenAccessLicense) Usage and distribution for commercial purposes as well as any distribution of modified material requires written permission. optineurin, and other proteins, presumably contributing to the pathogenesis of this disorder. The disease occurs in children and adults with any combination of leukoencephalopathy (dementia), cerebellum (ataxia), spinal intermediolateral (IML) nucleus, sacral Onuf's nucleus, and motor-sensory and autonomic neuropathy (variable manifestation including bladder dysfunction) [1-4]. This is the first urodynamic report to investigate bladder dysfunction in NIID.

\section{Case Report (Brief History Reported Previously [5])}

A 58-year-old man began to have staggering gait and memory problems 3 years prior. On admission, the MiniMental State Examination Score was 16 (performed repeatedly, normal $>24 / 30$ ). He had no motor paresis, tremor/rigidity, ataxia in speech/hands, or decreased superficial sensations. However, deep tendon reflexes were decreased in the lower extremities, and his gait was wide-based, staggering, and short-stepped with positive Romberg test. Blood tests to explore neurological etiologies were normal except for increased uric acid of $9.9 \mathrm{mg} / \mathrm{dL}$ (normal $<7.0$ $\mathrm{mg} / \mathrm{dL}$ ) and increased C-reactive protein of $6.27 \mathrm{mg} / \mathrm{dL}$ (normal $<0.1 \mathrm{mg} / \mathrm{dL}$ ). Whole-body computed tomography scans were normal. His cerebrospinal fluid examination showed a normal cell count, a normal glucose level, 
but increased total protein of $121 \mathrm{mg} / \mathrm{dL}$ (normal $<40 \mathrm{mg}$ / dL). Electroencephalography showed a slowed basic rhythm of 7-9 Hz. A nerve conduction study showed largefiber demyelination/axonal degeneration and motor/sensory neuropathy. Autonomic function tests suggested small-fiber neuropathy, with postural hypotension (systolic pressure fall of $25 \mathrm{~mm} \mathrm{Hg}$ ), and slow colonic transit time (79.2 h). Axial planes of T2-weighted and fluid-attenuated inversion recovery images on magnetic resonance imaging showed diffuse, high-signal-intensity white matter lesions, and diffusion-weighted magnetic resonance imaging showed linear, high-signal-intensity lesions in the corticomedullary junction. Skin biopsy showed eosinophilic hyaline intranuclear inclusions in the adipose cells, and the intranuclear inclusions stained positive for ubiquitin, which suggested NIID $[1,2]$. Although he did not complain his bladder problems, he was noticed to have voiding difficulty by nurses of the ward, and an ultrasound echography revealed a variable post-void residual (PVR) volume of 100-180 mL. Therefore, we performed a urodynamic study with his informed consent.

\section{First Urodynamic Study Results (during Hospitalization) (Fig. 1a)}

The patient showed bladder dysfunction on the first urodynamic study, with an Overactive Bladder Symptom Score of $1 / 15$ and an International Prostate Symptom Score of $7 / 35$, indicating mildly difficult urination. By the bowel part of a pelvic organ questionnaire, he had defecation difficulty (every time), decreased defecation frequency (once a 5 days), but no fecal incontinence/diarrhea. $\mathrm{He}$ did not answer the sexual part of the questionnaire. Prostate echography showed a prostate volume of $42.5 \mathrm{~mL}$ (normal $<20 \mathrm{~mL}$, symptomatic prostate hyperplasia $>30$ $\mathrm{mL}$ ). Analysis of the external sphincter electromyogram (EMG) revealed neurogenic motor-unit potentials. A urodynamic study was performed by the International Continence Society method [6]. The free-flow study showed a voided volume of $670 \mathrm{~mL}$, normal maximum flow rate $\left(Q_{\max }\right)$ of $19 \mathrm{~mL} / \mathrm{m}$ (normal $>10 \mathrm{~mL} / \mathrm{s}$ ), low average flow rate $\left(Q_{\text {ave }}\right)$ of $8 \mathrm{~mL} / \mathrm{m}$ (normal $>10 \mathrm{~mL} / \mathrm{s}$ ), and PVR of $56 \mathrm{~mL}$ (normal $<30 \mathrm{~mL}$ ). During slow filling (50 $\mathrm{mL} / \mathrm{min}$ ), with repeated questioning by the examiners, he reported his first sensation at $160 \mathrm{~mL}(100 \mathrm{~mL}<$ normal $<300 \mathrm{~mL}$ ), although it was equivocal and weak. Since he had not yet achieved maximum desire to void (bladder capacity) at the volume of $600 \mathrm{~mL}(200 \mathrm{~mL}<$ normal < $600 \mathrm{~mL}$ ), suggesting impaired bladder sensation, we stopped infusing saline into the bladder in order to avoid over-distension bladder injury. He had no detrusor overactivity even after a cough maneuver. We then asked him to void. However, he could not contract his bladder at all, suggesting underactive detrusor. During the voiding trial, sphincter EMG sounds decreased in amplitude. We could not perform pressure-flow analysis. He left a large PVR volume of $600 \mathrm{~mL}$. After he returned to the ward, he could void, but he still left a variable PVR volume of $50-280 \mathrm{~mL}$. Since our patient is unaware of his impaired bladder sensation, we instructed him to perform scheduled voiding. He was started on $990 \mathrm{mg} /$ day magnesium oxide, a stool softener, $15 \mathrm{mg} /$ day mosapride citrate, a selective 5 hydroxy tryptamine (serotonin)-4 receptor agonist, for ameliorating constipation, and $20 \mathrm{mg} /$ day memantine hydrochloride, a central $\mathrm{N}$-methyl-d-aspartate glutamate receptor antagonist, for ameliorating cognition, with benefit. He was discharged from the hospital.

\section{Second Urodynamic Study Results (5 Months Later)} (Fig. 1b)

Five months after hospitalization, he became incontinent of urine. He had an Overactive Bladder Symptom Score of $6 / 15$ and an International Prostate Symptom Score of $5 / 35$, showing urinary urgency/frequency. A free-flow study was not obtained. Soon after voluntary voiding, he had a PVR urine volume of $270 \mathrm{~mL}$ (normal $<30 \mathrm{~mL})$. During slow filling $(50 \mathrm{~mL} / \mathrm{min})$, he reported a first sensation at $511 \mathrm{~mL}(100 \mathrm{~mL}<$ normal $<300 \mathrm{~mL})$ and a maximum desire to void (bladder capacity) at $527 \mathrm{~mL}(200 \mathrm{~mL}<$ normal $<600 \mathrm{~mL})$ together with terminal detrusor overactivity and urinary incontinence, and we stopped infusing saline into the bladder. We asked him to continue to void (as a continuation of the incontinence episode); however, unfortunately, his catheter was pulled out spontaneously. During incontinence/ voiding, the sphincter EMG sound disappeared completely. We could not perform pressure-flow analysis. $\mathrm{He}$ had a voided volume of $545 \mathrm{~mL}$, normal maximum flow rate $\left(Q_{\max }\right)$ of $13 \mathrm{~mL} / \mathrm{m}$ (normal $>10 \mathrm{~mL} / \mathrm{s}$ ), low average flow rate $\left(Q_{\text {ave }}\right)$ of $6 \mathrm{~mL} / \mathrm{m}$ (normal $>10 \mathrm{~mL} / \mathrm{s}$ ), and PVR urine volume of $16 \mathrm{~mL}$ (normal $<30 \mathrm{~mL}$ ). Although he had a variable PVR, we started him on $25 \mathrm{mg} /$ day mirabegron, a selective beta3 adrenergic receptor agonist, for ameliorating urinary incontinence, with benefit. Three months later, he was re-admitted to our hospital for dehydration and moderate PVR. He was started on a Foley catheter and referred to another hospital. 
First sensation

$160 \mathrm{~mL}$ (equivocal)
Bladder

capacity $>600 \mathrm{~mL}$

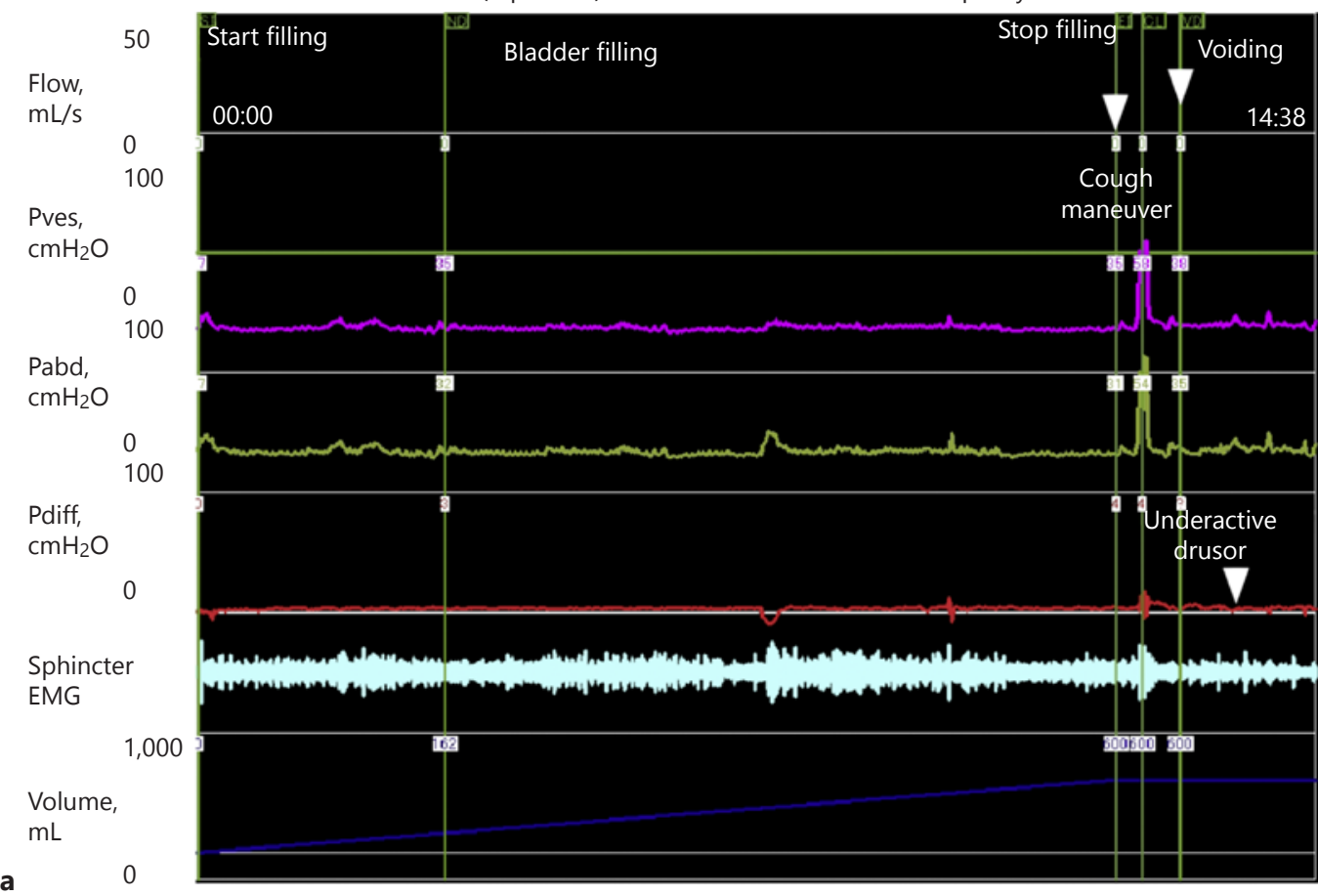

First

Bladder

sensation $511 \mathrm{~mL}$ capacity $527 \mathrm{~mL}$

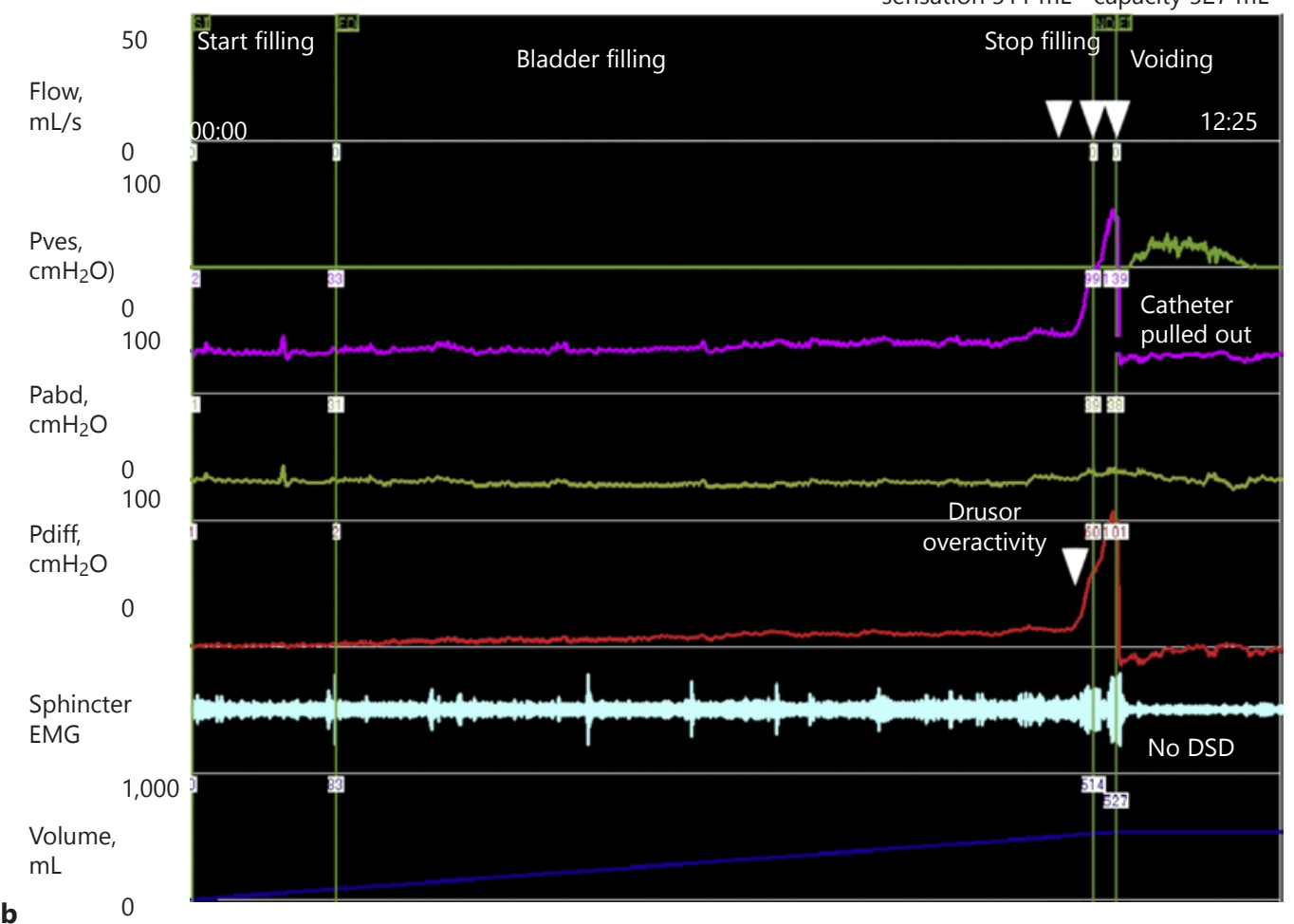




\section{Discussion}

Bladder dysfunction occurs in NIID. Previously, Sung et al. [7] reported a young woman with pathology-proven NIID who had stool incontinence and underwent Foley catheterization at the time of dementia and bed-ridden state. Sone et al. [1] reported 57 patients (5 pathologyproven, others with typical imaging/biopsy findings), of whom $56 \%$ had bladder dysfunction, 54\% had pupillary miosis, $33 \%$ had vomiting, and $5 \%$ had postural syncope; unfortunately, details of bladder dysfunction were not presented. Schuffler et al. [8] reported 2 siblings with pathology-proven NIID. Both had a 40-year history of postural hypotension, hypohidrosis, pupillary denervation hypersensitivity, and gastrointestinal dysfunction (dilated esophagus and small intestine that contracted uncoordinatedly and extensive colonic diverticulosis). Arrindel et al. [9] reported 6 patients (most with typical biopsy) who showed abnormal gastrointestinal manometry, color blindness, loss of light pupillary reflex, and abnormal electroretinogram. Zannolli et al. [10] reported 3 patients (one with typical biopsy) who had decreased sympathetic skin response (hypohidrosis), hypotensive episodes by $24-\mathrm{h}$ blood pressure monitoring, postural hypotension, and delayed/absent bulbocavernosus reflex of the penis. Nakamura et al. [11] reported 2 patients with typical imaging/ biopsy who had postural syncope and hypotensive episodes by 24 -h blood pressure monitoring. They also had urinary incontinence/retention, although details of bladder dysfunction were not presented. Our patient also had orthostatic hypotension, constipation, and bladder dysfunction. As far as we know, this is the first urodynamic report of NIID. The first urodynamic study of the patient showed decreased bladder sensation [12]: in particular, a large PVR, probably due to underactive detrusor, and neurogenic changes in the sphincter EMG. These findings, which became more pronounced in the second test, might be a reflection of an NIID lesion in the sacral spinal cord and/or distal nerve fibers innervating the lower urinary tract $[1,3,4,13]$. Five months later, he developed urinary

Fig. 1. Urodynamic recording of the patient. First urodynamic study results (during hospitalization). a During bladder filling, he reported a first sensation at $160 \mathrm{~mL}$, although it was equivocal and weak. He did not achieve maximum desire to void at the volume of $600 \mathrm{~mL}$, suggesting impaired bladder sensation. He had no detrusor overactivity. He could not contract his bladder at all, suggesting underactive detrusor with a large PVR volume of $600 \mathrm{~mL}$. Second urodynamic study results (5 months later). b During bladder fill- incontinence. The second urodynamic study showed detrusor overactivity. This finding might be a reflection of NIID lesions developing in the cerebral white matter, particularly in the frontal cortex that normally suppresses the micturition reflex $[13,14]$. From the bladder viewpoint, it is possible that the peripheral/sacral involvement is more prominent at the beginning, and with the progression of the disease, the suprapontine lesion load gets worse and is responsible for a change in the bladder dysfunction. In particular, his first bladder dysfunction, presumably 3 years prior, might be the loss of bladder sensation that the patient was unaware (damage in the peripheral/sacral autonomic sensory fibers), which is followed by a large PVR (damage in the peripheral/sacral autonomic motor fibers).

Although NIID causes dementia, it is important not only to address functional incontinence due to dementia [15] but also to treat neurogenic (either peripheral or central) causes of bladder dysfunction. Checking PVR is a recommended method for neurologists when facing patients with neurogenic bladder dysfunction [16, 17]. NIID is a disease that might cause progressive dementia, cerebellar ataxia, and peripheral neuropathy. Therefore, the following diseases should be differentiated with respect to patients' bladder problems. Among diseases that cause dementia, Alzheimer's disease is the most common, and Alzheimer's disease has overactive bladder in up to 40 percent of patients. In contrast, dementia with Lewy bodies and vascular dementia (white matter ischemia) have overactive bladder in up to 90 percent. These brain diseases rarely have urinary retention $[18,19]$. Among diseases that cause peripheral neuropathy, chronic inflammatory demyelination neuropathy and amyloid neuropathy may cause bladder dysfunction, with a combination of loss of bladder sensation and urinary retention [20].

In conclusion, for the first time, we urodynamically studied a case of NIID, showing a combination of detrusor overactivity, decreased bladder sensation, large PVR, and neurogenic changes in the sphincter EMG. This report will help managing bladder dysfunction in NIID. 


\section{Statement of Ethics}

This study was approved by the local ethics committee in the Sakura Medical Center, Toho University, and followed the Declaration of Helsinki. The patient and his carer gave written informed consent to publish his case (including publication of images).

\section{Conflict of Interest Statement}

We have nothing to declare. We have no conflict of interest.

\section{Funding Sources}

We have no funds relevant to this study.

\section{Author Contributions}

Y. Aiba participated in the acquisition of patients and/or data. R. Sakakibara participated in the study concept and design, acquisition of patients and/or data, analysis and interpretation of data, and preparation of the manuscript. F.C. Lee participated in the acquisition of patients and/or data. F. Tateno participated in the acquisition, analysis, and interpretation of data.

\section{References}

1 Pountney DL, Raftery MJ, Chegini F, Blumbergs PC, Gai WP. NSF, Unc-18-1, dynamin- 1 and HSP90 are inclusion body components in neuronal intranuclear inclusion disease identified by anti-SUMO-1-immunocapture. Acta Neuropathol. 2008;116(6):60314.

2 Sone J, Mori K, Inagaki T, Katsumata R, Takagi S, Yokoi S, et al. Clinicopathological features of adult-onset neuronal intranuclear inclusion disease. Brain. 2016;139(Pt 12):317086.

3 Sung JH. Autonomic neurons of the sacral spinal cord in amyotrophic lateral sclerosis, anterior poliomyelitis and "neuronal intranuclear hyaline inclusion disease": distribution of sacral autonomic neurons. Acta Neuropathol. 1982;56(3):233-7.

4 Parker JC Jr, Dyer ML, Paulsen WA. Neuronal intranuclear hyaline inclusion disease associated with premature coronary atherosclerosis. J Clin Neuroophthalmol. 1987;7(4): 244-9.

5 Aiba Y, Sakakibara R, Abe F, Higuchi T, Tokuyama W, Hiruta N, et al. Neuronal intranuclear inclusion disease with leukoencephalopathy and light motor-sensory and autonomic neuropathy diagnosed by skin biopsy. J Neurol Sci. 2016 Sep 15;368:263-5. Epub 2016 Jul 17.

6 Abrams P, Cardozo L, Fall M, Griffiths D, Rosier P, Ulmsten U, et al. The standardisation of terminology of lower urinary tract function: report from the standardisation sub-committee of the International Continence Society. Neurourol Urodyn. 2002; 21(2):167-78.
7 Sung JH, Ramirez-Lassepas M, Mastri AR, Larkin SM. An unusual degenerative disorder of neurons associated with a novel intranuclear hyaline inclusion (neuronal intranuclear hyaline inclusion disease). A clinicopathological study of a case. J Neuropathol Exp Neurol. 1980;39(2):107-30.

8 Schuffler MD, Bird TD, Sumi SM, Cook A. A familial neuronal disease presenting as intestinal pseudoobstruction. Gastroenterology. 1978;75(5):889-98.

9 Arrindell EL, Trobe JD, Sieving PA, Barnett JL. Pupillary and electroretinographic abnormalities in a family with neuronal intranuclear hyaline inclusion disease. Arch Ophthalmol. 1991;109(3):373-8.

10 Zannolli R, Gilman S, Rossi S, Volpi N, Bernini A, Galluzzi P, et al. Hereditary neuronal intranuclear inclusion disease with autonomic failure and cerebellar degeneration. Arch Neurol. 2002;59(8):1319-26.

11 Nakamura M, Ueki S, Kubo M, Yagi H, Sasaki R, Okada Y, et al. Two cases of sporadic adult-onset neuronal intranuclear inclusion disease preceded by urinary disturbance for many years. J Neurol Sci. 2018;392:89-93.

12 Tsunoyama K, Sakakibara R, Yamaguchi C, Uchiyama T, Yamamoto T, Yamanishi T, et al. Pathogenesis of reduced or increased bladder sensation. Neurourol Urodyn. 2011; 30(3):339-43.

13 de Groat WC, Griffiths D, Yoshimura N. Neural control of the lower urinary tract. Compr Physiol. 2015;5(1):327-96.
14 Sakakibara R. Lower urinary tract dysfunction in patients with brain lesions. Handb Clin Neurol. 2015;130:269-87.

15 Sakakibara R, Uchiyama T, Yamanishi T, Kishi M. Dementia and lower urinary dysfunction: with a reference to anticholinergic use in elderly population. Int J Urol. 2008;15(9): 778-88.

16 Fowler CJ, Panicker JN, Drake M, Harris C, Harrison SC, Kirby M, et al. A UK consensus on the management of the bladder in multiple sclerosis. J Neurol Neurosurg Psychiatry. 2009;80(5):470-7.

17 Sakakibara R, Panicker J, Finazzi-Agro E, Iacovelli V, Bruschini $\mathrm{H}$. A guideline for the management of bladder dysfunction in Parkinson's disease and other gait disorders. Neurourol Urodyn. 2016;35(5):551-63.

18 Takahashi O, Sakakibara R, Panicker J, Fowler CJ, Tateno F, Kishi M, et al. White matter lesions or Alzheimer's disease: which contributes more to overactive bladder and incontinence in elderly adults with dementia? J Am Geriatr Soc. 2012;60(12): 2370-1.

19 Tateno F, Sakakibara R, Ogata T, Kishi M, Tsuyusaki Y, Takahashi O, et al. Lower urinary tract function in dementia with Lewy bodies (DLB). Mov Disord. 2015;30(3):4115.

20 Lee FC, Sakakibara R, Tateno F, Aiba Y, Kishi $\mathrm{M}$, Suzuki $\mathrm{H}$, et al. Tafamidis improves bladder function in hereditary ATTR amyloidosis. Neurol Clin Neurosci. 2019;7(2):81-4. 